\title{
Endoscopic Vascular Decompression in Trigeminal Neuralgia
}

\author{
Yatin KHER ${ }^{1}$, Nishtha YADAV², Yad Ram YADAV1, Vijay PARIHAR ${ }^{1}$, Shailendra RATRE${ }^{1}$, Jitin BAJAJ1 \\ ${ }^{1}$ NSCB Medical College, Department of Neurosurgery, Jabalpur, Madhya Pradesh, India \\ ${ }^{2}$ All India Institute of Medical Science, Department of Radiodiagnosis and Imaging, New Delhi, India
}

\section{ABSTRACT}

\begin{abstract}
AIM: Microscope may fail to detect culprit vessel at the root entry zone or distally, especially when the suprameatal tubercle is prominent and when the compressing vessel is lying anteriorly to the trigeminal nerve without using significant brain retraction. Endoscopic techniques allow better visualization of the nerve and vascular conflict.
\end{abstract}

MATERIAL and METHODS: A retrospective study of 178 patients of endoscopic vascular decompression without the use of microscope was done. The follow-up period ranged from 12 to 108 months (average 58 months).

RESULTS: The age of the patients ranged from 32 to 75 years. Neuralgia was in the maxillary, mandibular and both (maxillary and mandibular) divisions in 89, 72 and 16 patients, respectively. Duration of the operation and hospital stay ranged from 85 to 160 minutes and 2 to 10 days (average 2.7 days), respectively. Offending vessels could be identified in 174 patients. The superior cerebellar artery, anterior inferior cerebellar artery, single vessel, double vessel conflicts and a vessel anterior to the nerve were seen in 136, 76, 133, 41 and 31 patients, respectively. The pain was relieved in 167 patients (93.8\%). Temporary complications included trigeminal dysesthesias (3.9\%), cerebrospinal fluid leak (2.8\%), facial paresis (3.9\%), decreased hearing (1.7\%) and vertigo (3.3\%). Permanent hearing loss, recurrence of pain and re-surgery was observed in 1, 7 and 3 patients, respectively.

CONCLUSION: Endoscopic vascular decompression is a safe and effective technique for vascular decompression with advantages of better visualization of the entire course of the nerve and vascular conflict without brain retraction. It also helps in better detection of the completeness of surgery.

KEYWORDS: Endoscopy, Microvascular decompression surgery, Skull base, Trigeminal neuralgia

\section{INTRODUCTION}

$\mathrm{M}$ icrovascular decompression (MVD) is a wellaccepted and highly effective surgical technique in trigeminal neuralgia (TN). Compression of the nerve by a vascular structure is the most accepted theory in the pathogenesis of TN. The microscope may fail to detect the compressing vessel at the root entry zone or distally especially when the suprameatal tubercle is prominent (43), and when culprit vessel is lying anterior to nerve (1). Drilling of the prominent suprameatal tubercle, (46) dissection of the cerebellar fissure and the supracerebellar route could be required to permit identification and dissection of neurovascular conflict (NVC) in such patients (19). Such additional procedures of drilling of bone and fissure dissection could be avoided when endoscope is used.

There are many advantages of the endoscope in TN, such as improved visualization of entire trigeminal nerve and vascular culprits $(1,6,12,16,28,59)$, which could be missed in significant percentages of the patients by microscope $(12,15,27,59)$. Improved visualization without brain retraction is a major advantage of endoscopic surgery (15). The endoscope also helps in better detection of whether the decompression is complete $(1,6,28,53,57)$. The endoscope can be used as a sole procedure $(2,6,28,32,35,53,68)$ or as an additional help to the microscope in TN $(1,4,10,12,16,27,34,42,50,59)$. An angled endoscope is very helpful in the diagnosis of offending 
vessels near the brain stem (62). The endoscopic technique is safe $(2,35,68)$, and needs less retraction of brain $(4,15,23$, $34,35)$, and is coupled with improved pain relief with a lower complication rate as compared to MVD (32).

This study aimed to evaluate our results of endoscopic vascular decompression (EVD) of the trigeminal nerve without the use of a microscope.

\section{MATERIAL and METHODS}

This was a retrospective study, which was performed in a tertiary care hospital, from July 2006 to December 2014. The ethics committee of our institute approved this study. Written consent was taken from all the patients.

Endoscopic surgeries were carried out when patients were not responding to medical treatment. Neurological examination was normal without any deficit in all patients. Magnetic resonance imaging (MRI) scans were performed before surgery in all patients with special attention to detect any NVC. Preoperative imaging was also aimed to rule out secondary causes. EVD, without any assistance of microscope, was performed in all patients who were medically fit for surgery. Medically unfit patients were subjected to percutaneous radiofrequency ablation or glycerol injection procedures. One patient required microscopic assistance to control severe bleeding from a ruptured petrosal vein.

Postoperative complications, such as cerebrospinal fluid (CSF) leak, cranial nerve deficit, infection and recurrence of pain, were assessed. The follow-up period ranged from 12 to 108 months (average of 58 months). Neuralgia secondary to aneurysm, tumors, other vascular malformation and multiple sclerosis were excluded. A brain retractor was also not used in any patient. Postoperative pain relief was assessed as per Barker et al. (5). It was graded as "complete" if the patient had $98 \%$ relief of pain without the need for any medication, "satisfactory" if greater than $75 \%$ relief with only intermittent use of pain medicine, and "none" if less then $75 \%$ pain relief or required continuous pain medication. Patients with atypical neuralgia were also excluded.

\section{Surgical Procedure}

We used the supine position with the head turned to the opposite side. A skin incision behind the ear of about $4 \mathrm{~cm}$ was created and about $3 \mathrm{~cm}$ bony opening was made. The dura mater was opened posterior to the junction of the sigmoid and transverse sinus. A zero degree $4 \mathrm{~mm}$ Karl Storz scope held by the telescope holder was employed after opening the dura mater. The brain was relaxed after removing CSF from the cisterna magna. The brain should be relaxed before starting any dissection near a nerve. A lumbar drain can also be used. Instruments were introduced from the sides of the scope. The arachnoid membrane near the trigeminal nerve was cut and dissected away from the nerve. Culprit vessels were identified and dissected from the nerve (Figure 1A-I). Preoperative imaging was helpful in finding out the involved area of the nerve and offending vessels and also in choosing the appropriate approach (17). Although preoperative knowledge of site of NVC by MRI could help in minimization of the dissection, vascular contacts were mostly distributed medial to the nerve in second branch neuralgia while it was in the lateral area in third branch neuralgia (80).

The $0^{\circ}$ scope was employed for most of the endoscopic procedure, the $30^{\circ}$ scope was helpful to visualize and dissect vascular conflict lying anterior to the nerve. The $30^{\circ}$ telescope was also helpful to see the nerve from the brain stem to Meckel's cave. The $0^{\circ}$ scope was positioned at the center of the operative field and instruments were introduced by the side of the telescope. The $30^{\circ}$ telescope was positioned at the corner of the surgical field. A dural patch of small size (G patch marketed by Surgiwear made up of polypropylene) was placed between the trigeminal nerve and the blood vessel. Tissue glue was applied to prevent migration of the interposed dura patch. We did not perform any intraoperative neuromonitoring scuh as brain stem auditory evoked potentials (BAEP) or facial electromyography (EMG).

\section{RESULTS}

There were $178 \mathrm{TN}$ patients who underwent the EVD procedure. One patient was suffering from both TN and hemifacial spasm. The age of the patients ranged from 32 to 75 years (average 58 years). There were 96 female patients and the pain distribution was unilateral in all patients. Right side lesions were seen in 102 patients while the left side was involved in 76 patients. Pain distribution was in maxillary, mandibular and both divisions (maxillary and mandibular) in 89, 72 and 16 patients respectively (Table I). There was one patient with ophthalmic division neuralgia. Duration of stay after surgery ranged from 2 to 10 days (average 2.7 days). Offending vessels were detected in 174 patients, while no culprit was observed in 4 patients. Partial root sectioning was performed in these 4 patients who failed to show any NVC during surgery. Superior cerebellar artery and anterior inferior cerebellar artery were observed as conflict in 136 and 76 patients, respectively. There was one patient with a tortuous basilar artery and 2 patients with small veins as the possible source of neuralgia. There were 133 and 41 single and double vessels respectively as a probable cause of neuralgia. NVC was lying anterior to the nerve in 31 patients $(17.4 \%)$, which could have been difficult to visualize with the help of microscope solely. We found an arterial loop in contact at the root entry zone, grooving, and displacement of nerves in 127,31 and 14 patients respectively. Although there were 6 patients with a prominent suprameatal tubercle, we were able to see the entire nerve from the pons to the ganglion without any brain retraction, additional bony drilling, or cerebellar fissure opening.

We were able to perform the whole procedure with the help of an endoscope without using the microscope (except in 1 case for severe bleeding) including release of CSF from the cisterna magna by inferiorly directing the scope, which helped us to avoid time wastage in changing from microscope to endoscope and back to microscope. Duration of surgery ranged from 85 to160 minutes (average 110 minutes). Complete and satisfactory pain relief was obtained in 159 and 8 patients out of a total of 167 patients (93.8\%). In 11 patients, pain relief 
was less then $75 \%$ and these patients required continuous pain medication. There was no death in the present study. Temporary complications included trigeminal dysesthesia in 7 patients $(3.9 \%)$. Other temporary complications were CSF leak, facial paresis, decreased hearing and vertigo in 5 , 7, 3, 6 patients, respectively. One patient continued to have a permanent decreased hearing. Recurrence of pain was observed in 7 patients (4\%) at follow-up ranging from 18-29 months. Re-surgery using endoscopic technique was done in 3 patients. We identified possible vascular loop, small dura patch granuloma, and dense arachnoid adhesions in each patient as a cause of recurrence in re-surgery. All 3 recurrent patients improved after surgery. There was no additional difficulty in re-surgery. There was bleeding from the petrosal vein in 2 patients in our EVD series. We were able to control it using an endoscopic technique in one patient while in another patient the help of a microscope was required to control bleeding.

\section{DISCUSSION}

Endoscopy is commonly used in skull base $(9,13,20,65)$, spine
$(38,66,70)$, and cranial surgery $(54,55,75,83)$. It is also useful for various types of pathologies such as congenital lesions $(26,48,71)$, hematomas evacuation $(73,84)$, tumor excisions $(3$, $74,76)$, and infective pathologies $(11,67,72)$.

Endoscopic techniques for TN were found to be safe in our study; other authors made similar observations $(2,6,35,53$, 68). The endoscopic procedure was very effective with good pain control rate in our study, as other authors have also observed $(1,6,28,53)$. Complete and satisfactory pain relief was observed in $93.8 \%$ of the patients in our series. Results of pain relief in various endoscopic or endoscope-assisted techniques were 84, 86, 90, 94, 95, 97, 99, 100, 100\% in the El-Garem et al. (16), Artz et al. (2), Balansard et al. (4), Yadav et al. (68), Kabil et al. (32), Chen et al. (12), Teo et al. (59), Miyazaki et al. (42), and Rak et al. (50) series respectively.

Although we used the interposition technique between the trigeminal nerve and the vascular conflict, sling transposition has been found to be better. The simple stitched sling retraction technique has been found to be a safe and effective treatment in TN (40). The stitched sling retraction technique can be used in recurrent cases after previous MVD (41).
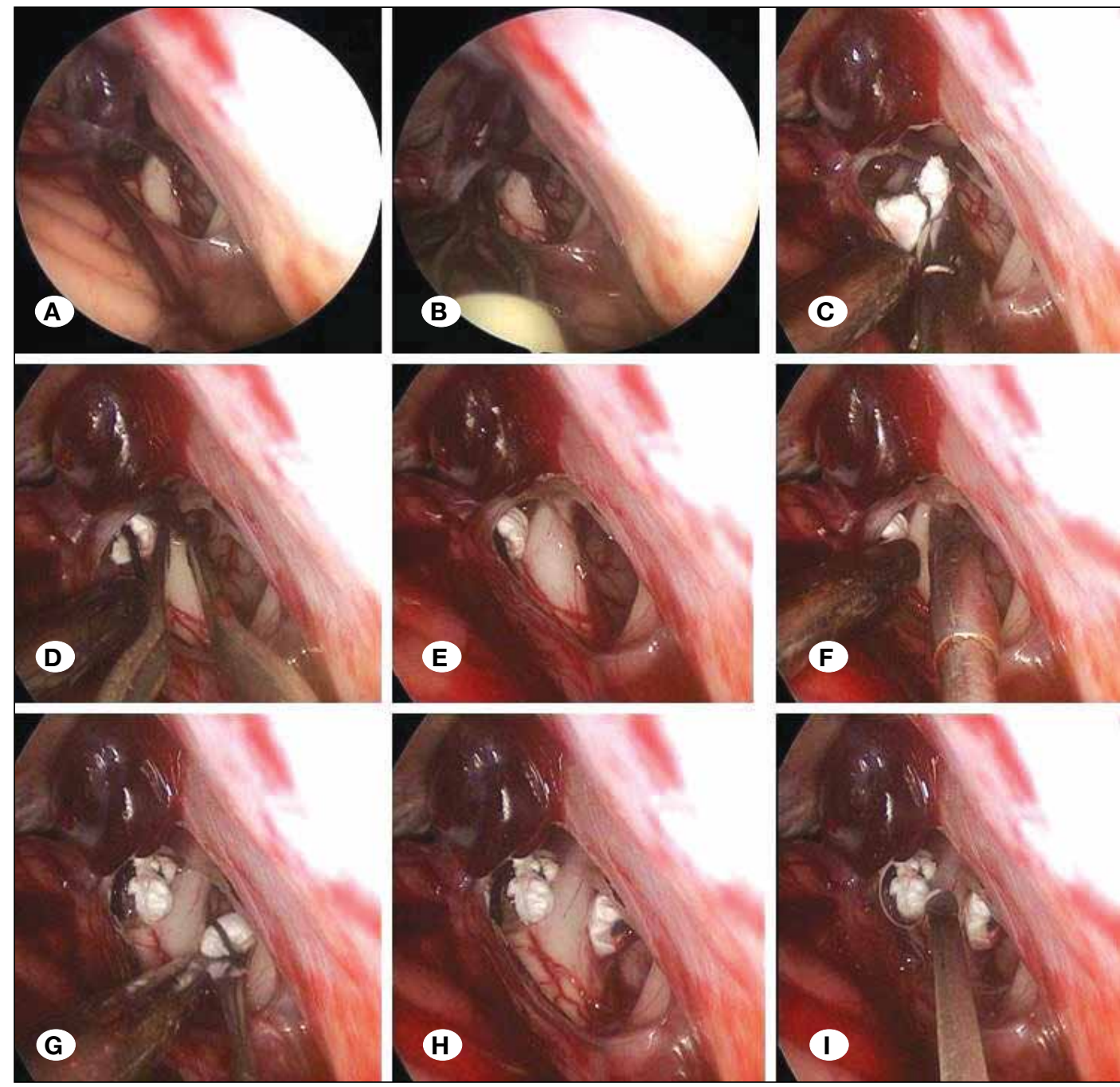

Figure 1: Endoscopic view showing (A) petrosal vein, trigeminal nerve and $7^{\text {th }}$ and $8^{\text {th }}$ nerve complex, dissection and interposition of a piece of dura patch between the trigeminal nerve and vascular conflict lying cranial (B, C, D, E) or caudal $(\mathbf{F}, \mathbf{G}, \mathbf{H}, \mathbf{I})$ to trigeminal nerve. 
Table I: Patient Demography, Operative Findings, Results and Complications of Endoscopic Vascular Decompression in Trigeminal Neuralgia

\begin{tabular}{|c|c|}
\hline Age & Ranged from 32 to 75 years (average 58 years). \\
\hline Nerve divisions involved & $\begin{array}{l}\text { Unilateral in all patients. } \\
\text { Right side: left side }=102: 76 \text { patients. } \\
\text { Maxillary }(n=89) \text {, mandibular }(n=72) \text {, both maxillary and mandibular divisions }(n=16) \text { and } \\
\text { ophthalmic division }(n=1) \text {. }\end{array}$ \\
\hline Intra- operative findings & $\begin{array}{l}\text { Offending vessels were detected in } 174 \text { patients. } \\
\text { Superior cerebellar and the anterior inferior cerebellar artery were observed in } 136 \text { and } 76 \\
\text { patients, respectively } \\
\text { Single and double vessels were present in } 133 \text { and } 41 \text { patients respectively. } \\
\text { Small veins in } 2 \text { patients. } \\
\text { Vascular conflict was lying anterior to the nerve in } 31 \text { patients (17.4\%). } \\
\text { Arterial loop in contact at the root entry zone, displacement and grooving of nerves in 127, } 14 \\
\text { and } 31 \text { patients respectively. }\end{array}$ \\
\hline Results & $\begin{array}{l}\text { Duration of operation ranged from } 85-160 \text { minutes (average } 110 \text { minutes). } \\
\text { Complete and satisfactory pain relief in } 159 \text { and } 8 \text { patients respectively. } \\
\text { Pain relief was less than } 75 \% \text { and required continuous pain medication in } 11 \text { patients. }\end{array}$ \\
\hline Complications & $\begin{array}{l}\text { No mortality. } \\
\text { Temporary complications: Trigeminal dysesthesias, cerebrospinal fluid leak, facial paresis, } \\
\text { decreased hearing and vertigo were observed in } 7,5,7,3,6 \text { patients respectively. } \\
\text { Permanent decreased hearing in } 1 \text { patient. } \\
\text { Recurrence of pain in } 7 \text { patients ( } 4 \% \text { ). } \\
\text { Bleeding from the petrosal vein in } 2 \text { patients. }\end{array}$ \\
\hline
\end{tabular}

The offending loop of artery can be retracted from the nerve and using a silk thread loop around it, can be suspended to the adjacent tentorium or dura mater. The sling technique can avoid recurrence secondary to granuloma due to interposing graft material.

There may be multiple vessels related to the nerve. All vessels in relation to the nerve up to Meckel's cave should be decompressed $(22,82)$. Small intraneural veins can be sacrificed. Partial sensory root sectioning $(81,79)$ or combing (29) may be preferred over extensive mobilization of the large culprit vein. Wrapping techniques (81) or longitudinal dissection of the vessel away from the nerve roots (30) has been described to be effective procedures to relieve TN caused by intraneural vessels. Distal atrophy of the trigeminal nerve at or near the exit of the porus trigeminus was found to be associated with worse outcome (14). Results of resurgery were good in our study, when done with the help of an endoscope. Similarly, results of re-MVD were equally effective and safe after failed MVD (18).

We were able to see the entire nerve from pons to ganglion without any brain retraction. Other authors have made similar observations $(1,6,12,16,28,59)$ including visualization of vascular conflict on the ventral aspect of the nerve (1). New NVC can be identified using an endoscope, which could be missed by microscope in $7.5-33 \%$ patients $(12,15,16,27,59)$.
The endoscope helps in improved visualization of NVC without brain retraction (15). Petrosal veins may block access to the root entry zone in the microscopic approach, which may require a cerebellar-fissures approach or sacrifice of the petrosal vein (85). The endoscopic approach is helpful in such patients without additional fissure opening or sacrifice of vein. Although we could detect NVC in most of the patients (except in 4 patients) without the use of intraoperative indocyanine green (ICG) angiography, the technique has been used during MVD for detection of arterial conflict (78). Endoscope assistance helped in better identification of completeness of decompression after surgery in TN $(1,6,28,53,56,57)$. In some cases, decompression was not found to be sufficient at the end of MVD using the microscope alone, while endoscopic examination revealed additional compression and further procedures were required for complete decompression of the nerve $(27,59)$.

Endoscopic technique can be performed with a smaller skin incision, smaller bony opening, minimal dura incision, no brain retraction, less need for manipulation of the nerve, without any need to split cerebellar fissures, and no drilling of the bony prominence to get access to the full course of the nerve and all conflicts, including those present on the ventral aspect of the nerve. We did not require dissection of any fissure or drilling of tubercle in our series, although 6 patients had 
a prominent tubercle. Similar observations using minimally invasive technique were made in other reported series using an endoscopic technique or endoscope assistance $(10,16)$. Preoperative MRI can be used to detect a prominent bony ridge, which can prevent visualization of a vascular conflict using a microscope; the endoscope is a valuable tool in such cases (52). Excision of this tubercle may be required to see conflicts when microscopic technique is performed, and such conflict can be missed otherwise. Distal conflicts near the ganglion are also difficult to visualize using the microscope alone and could demand use of the endoscope in such surgeries (43). We did not require any brain retraction in our series and similar observation were made in other series (1, $4,15,23,28,34)$. Smaller, precise and safe dural opening has been described with the help of ICG angiography, although we did not use it in our series (77).

Pure endoscopy or endoscope-assisted microvascular decompression has been found to be superior to decompression using a microscope $(1,4,12,16,27,32,34,42,50,59)$. In endoscope-assisted surgery, most of the procedure is done with the help of a microscope and the endoscope is introduced to see NVC and also to know whether proper decompression has been performed. This results in time wastage in changing from the microscope to the endoscope and back to the microscope. This time wastage can be avoided if the whole procedure can be done under endoscopic visualization. We were able to do the whole procedure with the help of endoscope without using a microscope, including release of CSF from the cisterna magna by inferiorly directing the scope towards the cistern.

Although we found the pure endoscopic technique to be safe and effective, microscopic decompression has been advocated as a technique of choice by Broggi et al. (8). However, same groups have advocated adjunctive use of an endoscope in confirming NVC, revealing conflicts missed by the microscope, and verifying adequate nerve decompression (8). Such observations are possible at the beginning of the learning curve in endoscope use because of difficulties in the learning period.

We are not against the use of a microscope; in fact, most of our other neurosurgical procedures are done with the help of a microscope. Once the learning curve is over, the use of a microscope will be an exceptional situation in the treatment of TN.

There was no mortality in our series; similar observations were made in other reported series as well $(1,32,42)$. Permanently decreased hearing was observed in one patient in our series. Hearing loss was also observed in other series $(6,59)$. Highfrequency hearing loss may result from drill-induced noise and/or transient loss of CSF (61). Preservation of the arachnoid over the vestibular nerve could help in minimizing hearing loss (7). Intraoperative neuro-electrophysiological monitoring such as BAEP, EMG for orbicularis oculi, orbicularis oris and masseter muscles could help improve results of MVD and decrease complications $(21,51)$. Combination of BAEP and endoscopic procedure could be helpful in difficult situations to restore hearing, better visualize the root entry zone and verify the location of the interposing graft (36). We had a few temporary complications such as trigeminal dysesthesia, facial paresis, decreased hearing and vertigo. Better visualization of the whole extent of nerve without brain retraction and minimal dissection of nerves could be responsible for the fewer complications in our series and in other reported endoscopic series $(2,16,32,42)$. Trigeminal dysesthesia developed in $8 \%$ of the patients in the Teo et al. series (59). Facial palsy was observed in $3 \%$ of the patients in the Abdeen et al. series (1).

The CSF leak rate in the present study was $2.8 \%$. The reported rate for CSF leak was 1, 2.4, 3.6, and 10\% in earlier endoscopic and endoscope-assisted surgery series by Yadav et al. (68), Balansard et al. (4), Miyazaki et al. (42), and El-Garem et al. (16) respectively. Muscle pieces interpositioned between the dura mater, use of artificial dura mater, cranioplasty, and sealing of mastoid sinus by bone wax and muscle can be effective techniques for the prevention of CSF leak $(37,49)$. Delayed removal of stiches and meticulous repair of the dura could be responsible for the lower incidence of CSF leak in our series. Although we did not come across complications such as cerebellar infarction, and cerebellar hemorrhage, these complications have been described after MVD (39).

Recurrence of pain was observed in 7 patients (4\%) in our study. Recurrence rates ranging from 18 to $34 \%$ have been reported at long-term follow up $(47,60)$. Re-displacement of the vascular loop, missing the NVC at the time of surgery, granuloma formation, and adhesion between the trigeminal root and fibrin glue or prosthesis can cause recurrence (45). Re-compression due to re-growth of new vein and artery can cause TN (25). A smaller volume of the cerebello-pontine angle cistern could be associated with recurrence as compared to a larger volume cistern (33). A hardened Teflon piece can pierce the nerve and produce recurrence (63). The prosthesis, when used, should be placed in the subarachnoid space or cistern avoiding contact to the trigeminal root to prevent recurrence (58). Recurrence in TN is more common within 2 years after surgery and thereafter the rate is about 2-3.5\% per year (47). Significant predictors of recurrence in TN are younger age, and symptoms lasting longer than 10 years (60). Compression of the trigeminal root entry zone by a vein, female gender, and lack of immediate postoperative pain relief are also associated with a higher rate of recurrence (31).

Transnasal endoscopic surgery for maxillary neuralgia could be an alternative approach to the rotundum foramen (24). Middle cranial fossa exploration (through a burr-hole centered at the base of the middle cranial fossa, $1 \mathrm{~cm}$ in front and $1 \mathrm{~cm}$ above the tragus) could offer an alternate surgical procedure to access the trigeminal ganglion (44). Endoscopic resection of the maxillary nerve and infraorbital nerve through the pterygopalatine fossa and the maxillary sinus has the advantages of avoiding craniotomy, which could be performed easily with good efficacy (64).

There are some limitations of this procedure such as instrument introduction to the field being blind proximal to the scope tip in a stand-held endoscopic procedure. This difficulty can be overcome by looking intermittently at the screen and at the operative field while introducing the instrument proximal to 
the telescope tip. Introduction of the instrument should be by the side of the scope, avoiding injury to the brain. Once the instrument is seen beyond the telescope tip one should look at the screen only. The telescope itself occupies some space, which is already limited. Telescope can block movements of micro-instruments due to the limited space (69). This difficulty in movement of instruments can be overcome by proper positioning of the scope. This procedure is associated with a steep learning curve. Cadaveric dissection, practice on models, and gaining experience from simpler endoscopic techniques can help in improving hand-eye coordination. Once the definite learning curve is achieved and expertise is acquired, the procedure becomes easy and safe (69). The telescope can be held by scope holder or by the assistant. In a hand-held endoscopic procedure, one has to depend on another expert assistant to hold the scope. We used a telescope holder in all our cases.

Limitations of the procedure conducted by scope held by holder are difficulties faced when there is brick bleeding. Blood can stain the telescope lens due to the small focal length. There can be fogging of the lens due to blood, surrounding tissue, humidity of air medium etc. in endoscopic procedures. A lens cleaner or manual cleaning by antifogging agents can help overcome this problem.

It is difficult to control brisk bleeding using an endoscopic technique because the blood soils the telescope lens. This can be overcome by intermittent irrigation of lens tip with warm saline and using 2 suctions. One should simply apply a cotton patty on Surgicel ${ }^{\circledR}$ (oxidized cellulose polymer marketed by Ethicon) at the bleeding point and should not try to coagulate the bleeding venous sinus.

An assistant holding the telescope is better in such a situation as he/she can move the scope according to requirement to prevent lens soiling. This may be difficult for the beginner; microscope help can be taken if one does not succeed in controlling bleeding by the endoscopic technique. Retrospective study and short follow up in some patients are some limitations of this study. Recurrence can occur very late with such procedures.

\section{CONCLUSION}

The endoscopic technique in trigeminal neuralgia is a safe and effective alternative procedure for microvascular decompression. It has the advantage of minimally invasive technique, which does not require drilling of the suprameatal tubercle even if it is prominent. It also avoids splitting of the cerebellar fissure for exposure of the root entry zone. The endoscope allows better visualization of the entire course of the nerve and NVC without brain retraction. It helps in better identification of the completeness of decompression after surgery.

\section{REFERENCES}

1. Abdeen K, Kato Y, Kiya N, Yoshida K, Kanno T: Neuroendoscopy in microvascular decompression for trigeminal neuralgia and hemifacial spasm: Technical note. Neurol Res 22:522-526, 2000

2. Artz GJ, Hux FJ, Larouere MJ, Bojrab DI, Babu S, Pieper DR: Endoscopic vascular decompression. Otol Neurotol 29:9951000, 2008

3. Azab W, Al-Sheikh T, Yahia A. Preoperative endoscopic third ventriculostomy in children with posterior fossa tumors: An institution experience. Turk Neurosurg 23:359-365, 2013

4. Balansard ChF, Meller R, Bruzzo M, Chays A, Girard N, Magnan J: Trigeminal neuralgia: Results of microsurgical and endoscopic-assisted vascular decompression. Ann Otolaryngol Chir Cervicofac 120: 330-337, 2003

5. Barker FG, Jannetta PJ, Bissonette DJ, Larkins MV, Jho HD: The long-term outcome of microvascular decompression for trigeminal neuralgia. N Engl J Med 334: 1077-1083, 1996

6. Bohman LE, Pierce J, Stephen JH, Sandhu S, Lee JY: Fully endoscopic microvascular decompression for trigeminal neuralgia: Technique review and early outcomes. Neurosurg Focus. 37: E18, 2014

7. Bond AE, Zada G, Gonzalez AA, Hansen C, Giannotta SL: Operative strategies for minimizing hearing loss and other major complications associated with microvascular decompression for trigeminal neuralgia. World Neurosurg 74: 172-177, 2010

8. Broggi M, Acerbi F, Ferroli P, Tringali G, Schiariti M, Broggi G: Microvascular decompression for neurovascular conflicts in the cerebello-pontine angle: Which role for endoscopy? ActaNeurochir (Wien) 155:1709-1716, 2013

9. Ceylan S, Anik I, Koc K, Ciftci E, Cabuk B: Endoscopic approach to cavernous sinus aneurysm. Turk Neurosurg 23: 404-406, 2013

10. Charalampaki P, Kafadar AM, Grunert P, Ayyad A, Perneczky A: Vascular decompression of trigeminal and facial nerves in the posterior fossa under endoscope-assisted keyhole conditions. Skull Base 18: 117-128, 2008

11. Chen G, Xiao Q, Zheng J, Wu J, Ao Q, Liu Y: Endoscopic transaqueductal removal of fourth ventricular neurocysticercosis: Report of three cases. Turk Neurosurg 25:488-492, 2015

12. Chen MJ, Zhang WJ, Yang C, Wu YQ, Zhang ZY, Wang Y: Endoscopic neurovascular perspective in microvascular decompression of trigeminal neuralgia. $\mathrm{J}$ Craniomaxillofac Surg 36: 456-461, 2008

13. Chowdhury FH, Haque MR, Kawsar KA, Ara S, Mohammod QD, Sarker $\mathrm{MH}$, Goel AH: Endoscopic endonasal transsphenoidal exposure of circle of Willis (CW); can it be applied in vascular neurosurgery in the near future? A cadaveric study of 26 cases. Turk Neurosurg 22:68-76, 2012

14. Duan Y, Sweet J, Munyon C, Miller J: Degree of distal trigeminal nerve atrophy predicts outcome after microvascular decompression for Type 1a trigeminal neuralgia. J Neurosurg 123: 1512-1518, 2015 
15. Duntze J, Litré CF, Eap C, Théret E, Bazin A, Chays A: Adjunctive use of endoscopy during microvascular decompression in the cerebellopontine angle: 27 case reports. Neurochirurgie. 57: 68-72, 2011 (In French)

16. El-Garem HF, Badr-El-Dine M, Talaat AM, Magnan J: Endoscopy as a tool in minimally invasive trigeminal neuralgia surgery. Otol Neurotol 23: 132-135, 2002

17. Feng $\mathrm{BH}$, Zheng XS, Liu M, Wang XQ, Wang XH, Ying TT, Li ST: Microvascular decompression for trigeminal neuralgia: Zone exploration and decompression techniques. J Craniofac Surg 26: 2381-2384, 2015

18. Fernández-Carballal C, García-Salazar F, Pérez-Calvo J, García-Leal R, Gutiérrez FA, Carrillo R: Management of recurrent trigeminal neuralgia after failed microvascular decompression. Neurocirugia (Astur) 15: 345-352, 2004 (In Spanish)

19. Fujimaki T, Kirino T: Combined transhorizontal-supracerebellar approach for microvascular decompression of trigeminal neuralgia. Br J Neurosurg 14: 531-534, 2000

20. Fuminari K, Hideki A, Manabu O, Mitsunori M: Extended endoscopic endonasal surgery using three-dimensional endoscopy in the intra-operative MRI suite for supradiaphragmatic ectopic pituitary adenoma. Turk Neurosurg 25:503-507, 2015

21. He X, Li N, Liang J, Wang Y, Cao W, Qu Y, Gao D, Ji X, Jiang $X$, Li B, Fu L, Zhang X, Liu W, Fei Z: Alarming effect of intraoperative neuroelectrophysiological monitoring in microvascular decompression for primary trigeminal neuralgia. Zhonghua Yi XueZaZhi 95: 1651-1654, 2015 (In Chinese)

22. Hong W, Zheng X, Wu Z, Li X, Wang X, Li Y: Clinical features and surgical treatment of trigeminal neuralgia caused solely by venous compression. ActaNeurochir (Wien) 153:10371042, 2011

23. Huang H, Hu ZQ, Zhu GT, Guan F, Dai B, Mao BB: Endoscopic microvascular decompression for trigeminal neuralgia. Zhonghua Yi XueZaZhi 91: 2491-2493, 2011 (In Chinese)

24. Huang RF, Zhang XM, Wen WP, Wang DF: Surgery for primary trigeminal maxillary neuralgia under transnasal endoscope. ZhonghuaEr Bi Yan HouTou Jing WaiKeZaZhi 44: 535-538, 2009 (In Chinese)

25. Inoue H, Kondo A, Shimano H, Yasuda S: Recurrent trigeminal neuralgia at 20 years after surgery: Case report. Neurol Med Chir (Tokyo) 53: 37-39, 2013

26. Jalessi M, Sharifi G, Jahanbakhshi A, Parsa K, Yazdanifard $P$ : Third ventricle herniation into the sphenoid sinus following endoscopic transnasal transsphenoidal fenestration of Rathke's cleft cyst. Turk Neurosurg 24:63-66, 2014

27. Jarrahy R, Berci G, Shahinian HK: Endoscope-assisted microvascular decompression of the trigeminal nerve. Otolaryngol Head Neck Surg 123: 218-223, 2000

28. Jarrahy R, Eby JB, Cha ST, Shahinian HK: Fully endoscopic vascular decompression of the trigeminal nerve. Minim Invasive Neurosurg 45: 32-35, 2002

29. Jie H, Xuanchen Z, Deheng L, Kun G, Fengyang X, Xiang C: The long-term outcome of nerve combing for trigeminal neuralgia. ActaNeurochir (Wien) 155:1703-1708, 2013
30. Jito J, Nozaki K: Trigeminal neuralgia due to intraneural trigeminocerebellar artery: Case report and review of the literature. World Neurosurg 88:687.e7-687.e11, 2016

31. Kabatas S, Albayrak SB, Cansever T, Hepgul KT: Microvascular decompression as a surgical management for trigeminal neuralgia: A critical review of the literature. Neurol India 57: 134-138, 2009

32. Kabil MS, Eby JB, Shahinian HK: Endoscopic vascular decompression versus microvascular decompression of the trigeminal nerve. Minim Invasive Neurosurg 48: 207-212, 2005

33. Kawano Y, Maehara T, Ohno K: Validation and evaluation of the volumetric measurement of cerebellopontine angle cistern as a prognostic factor of microvascular decompression for primary trigeminal neuralgia. Acta Neurochir (Wien) 156: 1173-1179, 2014

34. King WA, Wackym PA, Sen C,Meyer GA, Shiau J, Deutsch H: Adjunctive use of endoscopy during posterior fossa surgery to treat cranial neuropathies. Neurosurgery 49:108-115 discussion 115-116, 2001

35. Lang SS, Chen HI, Lee JY: Endoscopic microvascular decompression: A stepwise operative technique. ORL J Otorhinolaryngol Relat Spec 74:293-298, 2012

36. Lee CC, Liao CH, Lin CF, Yang TF, Hsu SP, Yen YS, Shih YH: Brainstem auditory evoked potential monitoring and neuroendoscopy: Two tools to ensure hearing preservation and surgical success during microvascular decompression. J Chin Med Assoc 77: 308-316, 2014

37. Li N, Zhao WG, Pu CH, Shen JK: Clinical application of artificial dura mater to avoid cerebrospinal fluid leaks after microvascular decompression surgery. Minim Invasive Neurosurg 48: 369- 372, 2005

38. Li Y, Wang B, Lv G, Xiong G, Liu W: Video-assisted thoracoscopic surgery for migration of a Kirschner wire in the spinal canal: A case report and literature review. Turk Neurosurg 23:803-806, 2013

39. Liang JF, Li G, Liu G, Shi W, Liu Q: Microneurosurgery for the trigeminal neuralgia and hemifacial spasm and glosspharyngeal neuralgia with endoscopic. Lin Chung Er Bi Yan HouTou Jing WaiKeZaZhi 28:332-335, 2014 (In Chinese)

40. Masuoka J, Matsushima T, Inoue K, Nakahara Y, Takase Y, Kawashima M: Outcome of microvascular decompression for trigeminal neuralgia treated with the stitched sling retraction technique. Neurosurg Rev 38: 361-365; discussion 365, 2015

41. Meybodi AT, Habibi Z, Miri M, Tabatabaie SA: Microvascular decompression for trigeminal neuralgia using the 'Stitched Sling Retraction' technique in recurrent cases after previous microvascular decompression. Acta Neurochir (Wien) 156: 1181-1187; discussion 1187, 2014

42. Miyazaki H, Deveze A, Magnan J: Neuro-otologic surgery through minimally invasive retrosigmoid approach: Endoscope assisted micro-vascular decompression, vestibular neurotomy, and tumor removal. Laryngoscope 115: 1612-1617, 2005

43. Moreira-Holguin JC, Revuelta-Gutierrez R, Monroy-Sosa A, Almeida-Navarro S: Suprameatal extension of retrosigmoid approach for microvascular decompression of trigeminal nerve: Case report. Int J Surg Case Rep 15:13-16, 2015 
44. Mourgela S, Sakellaropoulos A, Anagnostopoulou S: Middle cranial fossa endoscopy using a rigid endoscope. Minim Invasive Ther Allied Technol 16:355-359, 2007

45. Ohta M, Komatsu F, Abe H, Sakamoto S, Tsugu H, Oshiro $\mathrm{S}$ : Complication caused by use of fibrin glue in vessel transposition for trigeminal neuralgia. Neurol Med Chir (Tokyo) 48: 30-32, 2008

46. Oiwa $Y$, Hirohata $Y$, Okumura $H$, Yamaga $H$, Takayama M, Terui $\mathrm{K}$ : Bone drilling in microvascular decompression for trigeminal neuralgia: High morphological variety of the petrous bone. No Shinkei Geka 41: 601-607, 2013 (In Japanese)

47. Olson S, Atkinson L, Weidmann M: Microvascular decompression for trigeminal neuralgia: Recurrences and complications. J Clin Neurosci 12: 787-789, 2005

48. Ozdamar D, Etus V, Ceylan S, Solak M, Toker K: Anaesthetic considerations and perioperative features of endoscopic third ventriculostomy in infants: Analysis of 57 cases. Turk Neurosurg 22:148-155, 2012

49. Park JS, Kong DS, Lee JA, Park K: Intraoperative management to prevent cerebrospinal fluid leakage after microvascular decompression: Dural closure with a "plugging muscle" method. Neurosurg Rev 30: 139-142, 2007

50. Rak R, Sekhar LN, Stimac D, Hechl P: Endoscope-assisted microsurgery for microvascular compression syndromes. Neurosurgery 54: 876- 881 discussion 881-883, 2004

51. Ramnarayan R, Mackenzie I: Brain-stem auditory evoked responses during microvascular decompression for trigeminal neuralgia: Predicting post-operative hearing loss. Neurol India 54: 250-254, 2006

52. Sandell T, Ringstad GA, Eide PK: Usefulness of the endoscope in microvascular decompression for trigeminal neuralgia and MRI-based prediction of the need for endoscopy. Acta Neurochir (Wien) 156:1901-1909; discussion 1909, 2014

53. Setty P, Volkov AA, D'Andrea KP, Pieper DR: Endoscopic vascular decompression for the treatment of trigeminal neuralgia: Clinical outcomes and technical note. World Neurosurg 81:603-608, 2014

54. Setty P, Volkov A, Richards B, Barrett R: Minimally invasive treatment of biventricular hydrocephalus caused by a giant basilar apex aneurysm via a staged combination of endoscopy and endovascular embolization: A case report. Turk Neurosurg 25:344-349, 2015

55. Sharifi G, Alavi E, Rezaee O, Jahanbakhshi A, Faramarzi F: Neuroendoscopic foraminoplasty for bilateral idiopathic occlusion of foramina of Monro. Turk Neurosurg 22:265-268, 2012

56. ShimanskiĬ VN, Karnaukhov VV, Sergienko TA, Poshataev VK, Semenov VK: Endoscopically assisted removal of posterior fossa meningioma combined with microvascular decompression of trigeminal nerve root (early experience). ZhVoprNeirokhirlm N NBurdenko 75:70-74; discussion 74, 2011 (In Russian)

57. Shimanskiĭ VN, Karnaukhov VV, Sergienko TA, Poshataev VK, Semenov MS: Endoscopic assistance in microvascular decompression of cranial nerves. ZhVoprNeirokhirlm N NBurdenko 76: 3-10; discussion 10, 2012 (In Russian)
58. Sindou M, Leston JM, Decullier E, Chapuis F: Microvascular decompression for trigeminal neuralgia: the importance of a noncompressive technique-Kaplan-Meier analysis in a consecutive series of 330 patients. Neurosurgery 63:341-350, 2008

59. Teo C, Nakaji P, Mobbs RJ: Endoscope-assisted microvascular decompression for trigeminal neuralgia: Technical case report. Neurosurgery 59 (4 Suppl 2): ONS E489-ONS E490; discussion ONSE490, 2006

60. Theodosopoulos PV, Marco E, Applebury C, Lamborn $\mathrm{KR}$, Wilson CB: Predictive model for pain recurrence after posterior fossa surgery for trigeminal neuralgia. Arch Neurol 59: 1297-1302, 2002

61. Thirumala P, Meigh K, Dasyam N, Shankar P, Sarma KR, Sarma DR, Habeych M, Crammond D, Balzer J: The incidence of high-frequency hearing loss after microvascular decompression for trigeminal neuralgia, glossopharyngeal neuralgia, or geniculate neuralgia. J Neurosurg 123:15001506, 2015

62. Tutar H, Sahin M, Tutar VB, Bayazıt YA, Goksu N: Vascular compression syndromes: Our 24 year endoscope-assisted microvascular decompression experiences. Kulak Burun Bogaz Ihtis Derg 24: 6-10, 2014 (In Turkish)

63. Vitali AM, Sayer FT, Honey CR: Recurrent trigeminal neuralgia secondary to Teflon felt. Acta Neurochir (Wien) 149: 719-722, 2007

64. Wang Z, Ma W, Chang L, Xu L, Jian X, Zhang J, Ju F: The treatment of trigeminal neuralgia by resecting maxillary nerve and infraorbital nerve under the endoscopy at the pterygopalatofossa through approach to the maxillary sinus. Lin Chung Er Bi Yan HouTou Jing WaiKeZaZhi 28:113-114, 2014 (In Chinese)

65. Xuejian W, Fan H, Xiaobiao Z, Yong Y, Ye G, Tao X, Junqi G: Endonasal endoscopic skull base multilayer reconstruction surgery with nasal pedicled mucosal flap to manage high flow CSF leakage. Turk Neurosurg 23:439-445, 2013

66. Yadav YR, Madhariya SN, PariharVS, Namdev H, Bhatele PR: Endoscopic transoral excision of odontoid process in irreducible atlantoaxial dislocation: our experience of 34 patients. J NeurolSurg A Cent Eur Neurosurg 74: 162-167, 2013

67. Yadav YR, Parihar V, Agrawal M, Bhatele PR: Endoscopic third ventriculostomy in tubercular meningitis with hydrocephalus. Neurol India 59: 855-860, 2011

68. Yadav YR, Parihar V, Agarwal M, Sherekar S, Bhatele P: Endoscopic vascular decompression of the trigeminal nerve. Minim Invasive Neurosurg 54: 110-114, 2011

69. Yadav YR, Parihar V, Kher Y: Complication avoidance and its management in endoscopic neurosurgery. Neurol India 61: 217-225, 2013

70. Yadav YR, Parihar V, Namdev H, Agarwal M, Bhatele PR: Endoscopic interlaminar management of lumbar disc disease. J Neurol Surg A Cent Eur Neurosurg 74: 77-81, 2013

71. Yadav YR, Parihar V, Ratre S, Kher Y: Avoiding complications in endoscopic third ventriculostomy. J Neurol Surg A Cent Eur Neurosurg 76: 483-494, 2015

72. Yadav YR, Sinha M, Neha, Parihar V: Endoscopic management of brain abscesses. Neurol India 56:13-16, 2008 
73. Yadav YR, Yadav S, Sherekar S, Parihar V: A new minimally invasive tubular brain retractor system for surgery of deep brain lesions. Neurology India 59: 74-77, 2011

74. Yadav YR, Yadav N, Parihar V, Khare Y, Ratre S: Management of colloid cyst of third ventricle. Turk Neurosurg 25:362-371, 2015

75. Yildirim AE, Dursun E, Ozdol C, Divanlioglu D, Nacar OA, Koyun OK, IImaz AE, Belen AD: Using an autologous fibrin sealant in the preventing of cerebrospinal fluid leak with large skull base defect following endoscopic endonasal transsphenoidal surgery. Turk Neurosurg 23:736-741, 2013

76. Yildirim AE, Sahinoglu M, Divanlioglu D, Alagoz F, Gurcay AG,Daglioglu E, Okay HO, Belen AD: Endoscopic endonasal transsphenoidal treatment for acromegaly: 2010 consensus criteria for remission and predictors of outcomes. Turk Neurosurg 24:906-912, 2014

77. Yokoyama K, Kawanishi M, Yamada M, Tanaka H, Ito Y, Kuroiwa T: Indocyanine green videoangiography for vessel identification and reservation prior to dural opening for microvascular decompression. Turk Neurosurg 25:190-192, 2015

78. Zhang H, Fu WM, Chen P, Shi J: Intraoperative indocyanine green angiography during microvascular decompression surgery: Report of 30 cases. Acta Neurochir (Wien) 156:15611564, 2014
79. Zhang L, Zhang Y, Li C, Zhu S: Surgical treatment of primary trigeminal neuralgia: Comparison of the effectiveness between MVD and MVD+PSR in a series of 210 patients. Turk Neurosurg 22: 32- 38, 2012

80. Zhang W, Chen M, Zhang W, Chai Y: Trigeminal neuralgia: Evaluation of the relationship between the region of neuralgic manifestation and the site of neurovascular compression under endoscopy. J Craniofac Surg 26:1596-1599, 2015

81. Zheng X, Feng $B$, Hong $W$, Zhang W, Yang $M$, Tang Y: Management of intraneural vessels during microvascular decompression surgery for trigeminal neuralgia. World Neurosurg 77: 771-774, 2012

82. Zhong J, Li ST, Zhu J, Guan HX, Zhou QM, Jiao W: A clinical analysis on microvascular decompression surgery in a series of 3000 cases. Clin Neurol Neurosurg 114: 846-851, 2012

83. Zhou QJ, Liu B, Geng DJ, Fu Q, Cheng XJ, Kadeer K, DU GJ, Wang YX, Luan XP: Microsurgery with or without neuroendoscopy in petroclival meningiomas. Turk Neurosurg 25:231-238, 2015

84. Zhu H, Wang Z, Shi W: Keyhole endoscopic hematoma evacuation in patients. Turk Neurosurg 22:294-299, 2012

85. Zhu J, Zhong J, Jiao W, Zhou QM, Guan HX, Dou NN, Wang YN, Xia L, Li ST: Via-cerebellar-fissures approach for microvascular decompression of trigeminal nerve. J Craniofac Surg 25:1438-1440, 2014 